\title{
Prevalence and socio-demographic correlates of HIV among Tuberculosis patients of DOTS centre in Delhi
}

\author{
Vishal C Soyam', Jyoti Das², Rajeeva TC ${ }^{3}$, Pallavi Boro P4, Charu Kohli \\ ${ }^{1}$ Assistant Professor, Department of Community Medicine, MVJ Medical College and Research Hospital, Hoskote, Bangalore, ${ }^{2}$ Assistant \\ Director, National Centre for Disease Control, IDSP Department, New Delhi, ${ }^{3}$ Exclusive Faculty, Community Medicine at DAMS Institute \\ Bangalore, ${ }^{4}$ Senior Resident, Department of Community Medicine, Vardhaman Mahaveer Medical College New Delhi,, New Delhi, \\ ${ }^{5}$ Senior Resident, Department of Community Medicine, Maulana Azad Medical College and Associated L.N Hospitals, New Delhi
}

\section{A B S T R A C T}

Background: Knowledge of HIV status of a TB patient is critical from both patient and public health point of view. Early HIV diagnosis among TB patients could serve as an entry point for HIV care and treatment. Surveillance of HIV among TB patients has been recognized to be important as the HIV epidemic continues to fuel TB epidemics. Hence, this study was conducted with an objective to assess the socio-demographic profile and the prevalence of HIV among TB patients. Methodology: Cross sectional study was carried out in eight DOTS cum DMCs of Delhi. Data was collected from January 2012 to December 2012. Registered TB patients (new and retreatment) were interviewed on a predesigned questionnaire at the end of five months of treatment. Results: In 2012, out of the total 552 TB patients interviewed, $524(94.9 \%)$ had been tested for HIV by the end of fifth month of their TB treatment. In them, 13 patients (2.4\%) were HIV positive. All of them had been initiated on ART and CPT during continuation phase of TB treatment. In present study no variable was found to be significantly associated with HIV status except number family member and patients on retreatment category. Conclusions: The prevalence of HIV infection in TB patients in current study was $(2.4 \%)$ substantially lower than reported in studies from other states. If HIV testing done by all TB patients then routine reporting of HIV status for all TB patients would provide even better information on which to base future planning.

Key words: HIV prevalence, Tuberculosis, DOTS Centre, Socio demographic determinants
Access this article online Website:

http://nepjol.info/index.php/AJMS DOI: 10.3126/ajms.v7i1.12744

\section{INTRODUCTION}

Tuberculosis (TB) is the commonest and earliest opportunistic infection affecting Human Immunodeficiency Virus (HIV) patients in India. Out of the estimated 1.85 million TB cases occurring annually, approximately $5.2 \%$ (>96,000 persons) of them are HIV infected. ${ }^{1}$ Although the countrywide prevalence remains less than $1 \%(0.91 \%)$ in general population, there is wide variation in prevalence of HIV infection among TB patients in different states of India ranging from $1 \%$ to $13.8 \%$ while average rate is $5.2 \%{ }^{2,3}$ For Indians infected with HIV, the risk of developing TB increases to $50-60 \%{ }^{4,5}$

Knowledge of HIV status of a TB patient is critical from both patient and public health point of view.
Detection of HIV infection among TB patients offers the opportunity to deliver prompt HIV care, such as Cotrimoxazole Prophylaxis and Antiretroviral Treatment, which can reduce suffering and death. ${ }^{2}$ In Delhi, out of total registered TB patients in 2010, only $58 \%$ patient knew their HIV status despite HIV testing provided free of cost by the NACP (National AIDS Control Programme). Among those tested, 2\% were HIV positive. ${ }^{6}$ The prevalence of HIV among TB patients could be more, because $42 \%$ of TB patients are reported to be unaware of their HIV status and other reason being high rate of immigration from other states. Surveillance of HIV among TB patients has been recognized to be important as the HIV epidemic continues to fuel TB epidemics. In many countries, HIV prevalence among TB patients is a sensitive indicator of the spread of HIV 
into the general population. ${ }^{7}$ Knowledge of a person's HIV status also provides the opportunity to administer prophylaxis for opportunistic infections and thereby reduces morbidity and mortality. ${ }^{8}$ New cross referral strategy was formulated in Delhi by RNTCP and SACS to detect and treat HIV in TB patients. ${ }^{9}$ This provides opportunity to detect true prevalence of HIV in TB patients. Programmatic planning requires the availability of up-to-date data on HIV prevalence among different populations of $\mathrm{TB}$ patients. However, there is paucity of studies about the socio demographic determinants of HIV among TB patients in Delhi. Hence, this study was conducted with an objective to assess the sociodemographic profile and the prevalence of HIV among TB patients in Delhi.

\section{MATERIALS AND METHODS}

This was a cross sectional study carried out at six DOTS cum Designated Microscopy Centres under Chest Clinic of Lok Nayak Hospital, New Delhi and two DOTS cum Designated Microscopy Centers located in rural area, one at Rural Health Training Centre (R.H.T.C), Barwala and other at Maharaishi Valmiki Hospital (M.V.H.) Pooth Khurd., The study population consisted of all patients with TB registered for DOTS treatment under RNTCP in selected centres. Patients who have completed five months of DOTS therapy were included in the study. Patient with 'known HIV status' (defined as any prior positive test result or as a negative result for a test performed within six months prior to diagnosis of $\mathrm{TB}$ ) and children $<2$ years were excluded from the study. Only those TB patients whose HIV status was not known at the time of TB diagnosis were included in the analysis to draw the true prevalence of HIV infection among TB patients. Data was collected, over a period of one year from January to December 2012. The primary outcome variable was prevalence of HIV at the end of five month of anti-TB treatment. It was assumed that patients who did not get tested for HIV at the end five month of treatment, then it was unlikely that he/she will get himself/herself tested in future as well. Hence, in the present study, the time limit for defining the outcome variable was the end of five months. At 95\% confidence interval and taking the prevalence of non-uptake of HIV testing in TB patients as 43\% (According to 2010 RNTCP performance report of Delhi), with an allowable error of $10 \%$, total sample size was calculated to be 530 . A pretested semi-structured questionnaire prepared in both English and Hindi was used to interview registered TB patients to find out prevalence of HIV infection and its socio demographic determinants. Sample was taken from each centre proportionately according to patients registered in the previous year. Extra subjects were included for those

who had died or defaulted before the end of five month. Information was collected from the TB treatment card for those who had died and defaulted. The subjects were interviewed after taking informed consent from patients and from parents (patient were 15 years) The information collected from patients were verified and co-related with TB treatment card available at DOTS clinic. The investigator interviewed registered TB patients (both pulmonary as well as extra-pulmonary) at the end of 5 month of DOTS treatment in both category 1 and category 2 patients and in case of children their parents were interviewed. The questionnaire included items on socio-demographic profile such as age, sex, religion, marital status, per capita income, education and occupation.

Data was analyzed using SPSS software (version 16.0). Data was expressed in terms of mean $+\mathrm{SD}$ and percentages. For qualitative data, chi-square or Fischer exact test was used to observe the difference between the proportions. $\mathrm{P}$ value $<0.05$ was considered significant.

A written informed consent was taken from all the study subjects and in case of children, from their parents. The option to opt out of the study was kept open without any clause. Confidentiality was ensured and the collected data has been used for research purpose only. Ethical approval from institutional review board was obtained.

\section{RESULTS}

A total of 552 study subjects were thus included for analysis. Out of 552 patients, 24 died/defaulters before five month of treatment leaving 528. Data was collected of those died and defaulted from the TB treatment card from the DOTS centre (age, sex, religion, diagnosis of TB, and treatment category). For other variables, we took 528 as sample for analysis.

Socio demographic characteristics of study subjects The mean age of the study subjects was $29.35 \pm 14.8$ years. $199(36.1 \%)$ subjects were in the age group of 15-24 years. More than half $(52 \%)$ of study subjects were males, Hindu $(58 \%)$, literate $(77.5 \%)$, unemployed $(53.6 \%)$, including $76(26.8 \%)$ housewives. $75.2 \%$ belonged to lower socio economic class, with a monthly per capita income of less than 2055 rupees (Table 1).

Of the total 552 subjects, there were 320 (58.0\%) pulmonary TB cases and $232(42.0 \%)$ extra pulmonary TB cases. $9(1.6 \%)$ had died and $15(2.7 \%)$ had defaulted before completing 5 months of treatment. Among 320 pulmonary TB cases, $272(85.0 \%)$ were smear positive and $48(15.0 \%)$ were smear negative (Table 2$)$. 
Of the total subjects, $382(69.2 \%)$ were under category I while 170 (30.8\%) were in category II regimen. $62(73.8 \%)$ subjects in category I and $22(26.2 \%)$ in category II belonged to rural area and $320(68.4 \%)$ in category I and $148(31.6 \%)$ in category 2 belonged to urban area.

Out of 552 study subjects, 28 (4.1\%) subjects not had undergone HIV testing leaving 524 for further analysis. Out of 28 subjects, 15 subjects were died/defaulter before end

\begin{tabular}{|c|c|c|c|}
\hline \multirow{2}{*}{$\begin{array}{l}\text { Socio-demographic } \\
\text { characteristics }\end{array}$} & \multicolumn{3}{|c|}{ No (\%) } \\
\hline & $\begin{array}{l}\text { Rural } \\
(n=84)\end{array}$ & $\begin{array}{l}\text { Urban } \\
(n=468)\end{array}$ & $\begin{array}{c}\text { Total } \\
(\mathrm{N}=552)\end{array}$ \\
\hline \multicolumn{4}{|l|}{ Age groups (in years) } \\
\hline $2-14$ & $7(8.3)$ & $53(11.3)$ & 60 (10.9) \\
\hline $15-44$ & $65(77.4)$ & $325(69.5)$ & $390(70.6)$ \\
\hline 45 and above & $12(14.3)$ & $90(19.2)$ & $102(18.5)$ \\
\hline \multicolumn{4}{|l|}{ Gender } \\
\hline Male & $51(60.7)$ & $236(50.4)$ & $287(52.0)$ \\
\hline Female & $33(39.3)$ & $232(49.6)$ & $265(48.0)$ \\
\hline \multicolumn{4}{|l|}{ Religion } \\
\hline Hindu & $77(91.7)$ & $243(52.0)$ & $320(58.0)$ \\
\hline Muslim & $6(7.1)$ & $222(47.4)$ & $228(41.3)$ \\
\hline Other & $1(1.2)$ & $3(0.6)$ & $4(0.7)$ \\
\hline \multicolumn{4}{|c|}{ Educational status $(\mathrm{N}=524)^{*}$} \\
\hline Illiterate & $22(27.5)$ & $96(20.5)$ & $118(21.4)$ \\
\hline Primary & $16(20.0)$ & $86(18.4)$ & $102(18.8)$ \\
\hline Middle & $18(22.5)$ & $98(20.9)$ & $116(21.0)$ \\
\hline High school & $12(15.0)$ & $89(19.9)$ & $101(18.3)$ \\
\hline Senior secondary & $8(10.0)$ & $50(11.2)$ & $58(10.5)$ \\
\hline Graduate and above & $3(3.8)$ & $26(5.8)$ & $29(5.2)$ \\
\hline \multicolumn{4}{|l|}{ Marital status $(\mathrm{N}=528)^{\star *}$} \\
\hline Single & $29(36.2)$ & $213(47.5)$ & $242(45.9)$ \\
\hline Married & $51(63.8)$ & $219(48.9)$ & $270(51.1)$ \\
\hline Separated & $0(0)$ & $5(1.0)$ & $5(0.9)$ \\
\hline Widow & $0(0)$ & $11(2.6)$ & $11(2.1)$ \\
\hline \multicolumn{4}{|c|}{ Socio-economic class $€(N=528)$} \\
\hline Lower class & $5(6.2)$ & $68(15.2)$ & $73(13.8)$ \\
\hline Upper lower class & $58(72.5)$ & $266(59.3)$ & $324(61.4)$ \\
\hline Lower middle class & $12(15.0)$ & $83(18.5)$ & $95(18.0)$ \\
\hline Upper middle class & $3(3.8)$ & $28(6.3)$ & $31(5.9)$ \\
\hline Upper class & $2(2.5)$ & $3(0.7)$ & $5(0.9)$ \\
\hline
\end{tabular}

*Subjects $(n=4)$ aged up to 6 years and died and default $(n=24)$ not included, **Died and default ( $n=24)$ not included. $€$ Socio economic status was classified according to Mahajan Gupta Scale (2010)

Table 2: Distribution of study subjects according
to their diagnosis $(\mathrm{N}=\mathbf{5 5 2})$

of five months. HIV status was known for 524 subjects of which 13 (2.4\%) were HIV positive. Off the 524 subjects, 13 subjects were died and defaulter. Hence for some variables, the total numbers of subjects were taken as 515 because other data was not available.

Prevalence of HIV among TB patients were found to be $2.4 \%$. Prevalence of $\mathrm{HIV}$ in rural area $(4.1 \%)$ was higher than urban area $(2.2 \%)$ but the difference was not significant (Table 3). The HIV positive cases were more among males $(3.6 \%)$ as compared to females $(1.2 \%)$ but the difference was not significant. Majority of HIV positive cases belonged to age group 15- 44 years (92.3\%). The HIV positivity rates were higher among married (69.2\%), Hindus (84.6\%) and among lower socio-economic class $(83.3 \%)$. The significant difference was observed only for number of family member variable. Maximum numbers of HIV positive cases were observed in patients with 1-2 family members.

Table no 4 shows maximum numbers of HIV cases were observed among extra pulmonary TB cases $(53.8 \%)$ but the difference was not found significant. The HIV prevalence among category II treatment group (4.5\%) was higher than category I treatment group and this difference was found significant $(\mathrm{p}=0.05)$.

\section{DISCUSSION}

This study provides the information regarding prevalence of HIV infection and its socio demographic determinants among Tuberculosis patients. Study reveal a very high uptake of HIV testing (94.9\%) among tuberculosis patients, it may be because of HIV uptake at the end of five month was the outcome variable we consider for the study titled "Impact of new strategy on provider initiated HIV testing among Tuberculosis patients in Delhi" (Soyam $\mathrm{V} C$ et al., manuscript submitted in AIDS Care). The present study demonstrated that HIV prevalence (newly diagnosed HIV) among TB patients at DOTS centre in 2012 to 2013 was $2.4 \%(13 / 524)$ at the end of five month of tuberculosis treatment. From above finding it is clear that TB patients are an efficient source for HIV case-finding through this referral strategy of TB-HIV intensified package in India. If HIV testing uptake is high, routine reporting of HIV status for all TB patients would provide even better information on which to base future planning. ${ }^{2}$ According to RNTCP annual report 2012, Proportion of TB patients known to be HIV infected among tested was $2 \%$ consistent with present study. ${ }^{10}$ In a study from India it was found that HIV prevalence among TB patients was $9.0 \%$ in the highest prevalence states, $2.9 \%$ in the other states, and $4.9 \%$ overall. ${ }^{11}$ Present 


\begin{tabular}{|c|c|c|c|}
\hline \multirow[t]{2}{*}{$\begin{array}{l}\text { Socio demographic } \\
\text { characteristics }\end{array}$} & \multicolumn{2}{|c|}{$\begin{array}{l}\text { HIV status }(\mathrm{N}=524) \\
(\text { no. }(\%))\end{array}$} & \multirow{2}{*}{$\begin{array}{c}\text { P value } \\
\text { (Fisher } \\
\text { exact } \\
\text { test) }\end{array}$} \\
\hline & $\begin{array}{c}\text { HIV } \\
\text { positive } \\
(n=13)\end{array}$ & $\begin{array}{c}\text { HIV } \\
\text { negative } \\
(n=511)\end{array}$ & \\
\hline \multicolumn{4}{|l|}{ Residence $(n=524)$} \\
\hline Rural $(n=74)$ & $3(4.1)$ & $71(95.9)$ & 0.27 \\
\hline Urban $(n=450)$ & $10(2.2)$ & $440(97.8)$ & \\
\hline \multicolumn{4}{|l|}{ Age $(n=524)$} \\
\hline $2-14$ yrs & $1(1.8)$ & $54(98.2)$ & 0.2 \\
\hline $15-44$ yrs & $12(3.2)$ & $365(96.8)$ & \\
\hline$>45$ yrs & $0(0.0)$ & $92(100.0)$ & \\
\hline Gender $(n=524)$ & & & 0.06 \\
\hline Male & $10(3.6)$ & $264(96.4)$ & \\
\hline Female & $3(1.2)$ & $247(98.8)$ & \\
\hline \multicolumn{4}{|l|}{ Marital status $(n=515)^{*}$} \\
\hline Single $(n=235)$ & $2(0.9)$ & $233(99.1)$ & 0.08 \\
\hline Married $(n=266)$ & $9(3.4)$ & $257(96.6)$ & \\
\hline Others $(n=14)$ & $1(1.7)$ & $13(92.9)$ & \\
\hline \multicolumn{4}{|l|}{ Religion $(n=524)$} \\
\hline Hindu & $11(3.7)$ & $289(96.3)$ & 0.12 \\
\hline Muslim & $2(0.9)$ & $218(99.1)$ & \\
\hline Others & $0(0.0)$ & $4(100.0)$ & \\
\hline \multicolumn{4}{|c|}{ Occupational status $(n=511)^{*} €$} \\
\hline Employed & $5(3.0)$ & $160(97.3)$ & \\
\hline Unemployed & $6(2.2)$ & $271(97.8)$ & \\
\hline Student & $1(1.4)$ & $68(98.6)$ & \\
\hline \multicolumn{4}{|c|}{ Number of family member* } \\
\hline $1-2$ & $3(12.0)$ & $22(88.0)$ & 0.001 \\
\hline $3-6$ & $9(2.5)$ & $344(97.5)$ & \\
\hline$>6$ & $0(0.0)$ & $137(100.0)$ & \\
\hline \multicolumn{4}{|c|}{ Total per capita income* } \\
\hline$<1999$ Rs & $10(2.9)$ & $330(97.1)$ & 0.5 \\
\hline 2000-2999 & $1(1.0)$ & $98(99.0)$ & \\
\hline 3000-3999 & $0(0.0)$ & $36(100.0)$ & \\
\hline$>4000$ & $1(2.5)$ & $39(97.5)$ & \\
\hline
\end{tabular}

*Died and defaulter not included. €occupational status was not applicable for 4 subjects who were less than 6 yrs

\begin{tabular}{|c|c|c|c|}
\hline \multirow{2}{*}{$\begin{array}{l}\text { Tuberculosis } \\
\text { characteristics }\end{array}$} & \multicolumn{2}{|c|}{ HIV status (no. (\%)) } & \multirow{2}{*}{$\begin{array}{c}\text { Chi square } \\
\text { test } \\
\text { (P value) }\end{array}$} \\
\hline & $\begin{array}{c}\text { HIV } \\
\text { positive } \\
(n=13)\end{array}$ & $\underset{\substack{\text { HIV } \\
(n=511)}}{\text { negative }}$ & \\
\hline \multicolumn{4}{|l|}{ Diagnosis of TB $(n=524)$} \\
\hline Pulmonary positive & $4(1.6)$ & $252(98.4)$ & 0.3 \\
\hline Pulmonary negative & $2(4.3)$ & $44(95.7)$ & \\
\hline Extra pulmonary & $7(3.2)$ & $215(96.8)$ & \\
\hline \multicolumn{4}{|c|}{ Treatment category $(n=524)$} \\
\hline Category I & $6(1.6)$ & $362(98.4)$ & 0.05 \\
\hline Category II & $7(4.5)$ & $149(95.5)$ & \\
\hline
\end{tabular}

study finding of $2.4 \%$ consistent with the prevalence of $2.9 \%$ in other state. The prevalence of HIV infection in TB subjects observed in this study was substantially lower than that reported in study of Mumbai by Shrivastava SR et al $(10.2 \%)$ and in a retrospective analysis of TB cases in a tertiary care hospital by Sawant SS et al $(9.0 \%){ }^{2,12}$ The
HIV positivity in TB patients by seroprevalence studies shows wide variations in Delhi from $0.4 \%$ in 1995-1999, 0.68 in $1997-98$, to $9.4 \%$ in $2000-2002$, and $8.3 \%$ in $2003-2005{ }^{13-16}$ From above data it is clearly evident that HIV prevalence among TB patients is increased from 1995 to 2005. However present study found lower prevalence of HIV in TB patients than study conducted by Sharma SK et al and Piramanayagam P et al. ${ }^{15,16}$ This high prevalence of HIV infection in TB patients in Delhi is because of these studies conducted among adult patients and in tertiary care teaching hospitals. However findings $(2.4 \%)$ in present study support the current study conducted in Delhi from May 2012 to Jan 2013 by Gupta et al shows $92.2 \%$ TB patients referred and tested in ICTC of which 1.6\% TB patients were HIV positive. ${ }^{9}$ As evident from above, it is clear that the prevalence of HIV in TB patients has started decreasing in Delhi.

It was found that HIV prevalence rate among TB patients was more in rural area $(4.1 \%)$ as compared to urban area $(2.2 \%)$. This is probably related to selection of area, the area which was selected for present study was Bawana industrial area were immigration from other state is very high that might be reason for high HIV prevalence in rural area. Study from Jammu and Kashmir also showed rural dominance in the prevalence of HIV among pulmonary tuberculosis cases similar to current study. ${ }^{17}$

In the present study, majority of the co-infected cases were in the age group of $18-45$ years $(3.2 \%)$. This data suggests that it is better to target TB patients aged between 18 and 45 years for HIV prevention, as $92.3 \%$ of the cases were found in this age group. This is a sexually active group in which both TB and HIV prevail the most. ${ }^{18}$ Some other studies also reported similar findings that TB-HIV co-infection was more among sexually active age group. ${ }^{19-21}$

Sentinel surveillance study conducted in Delhi by Jain SK et al in 1997-98 suggested a higher risk of HIV co-infection present among males suffering from tuberculosis which is consistent with the present study. ${ }^{14}$ In addition to this, a study done at national level across all districts in India, HIV sero-prevalence in TB patients was highest in the groups aged 25-34 years (11.0\%) and 35-44 years (10.6\%). HIV sero-prevalence was higher among male TB patients than among female TB patients ( $8.4 \%$ vs. 5.6\%, RR 1.28, $95 \%$ CI 1.04-1.59). ${ }^{2}$

In present study no variable was found to be significantly associated with HIV status except number of family member. It was found that those who are staying alone or staying with one person had higher risk of getting HIV 
infection. However, it may be because of HIV and TB infection stigma, family members were not staying with the patients.

Present study reported higher prevalence of HIV among pulmonary smear negative $(4.3 \%)$ and extra pulmonary TB $(3.2 \%)$ patients. HIV prevalence among pulmonary TB patients was $1.6 \%$ in present study which is higher than findings reported from China of $0.5 \%{ }^{22} \mathrm{HIV}$ positivity rate was more among TB patients who were taking category II treatment $(4.5 \%)$ as compared to category I treatment $(1.6 \%)$ and this difference was found to be significant $(\mathrm{p}<0.05)$.

This study has considerable strengths such as random selection of participants from DOTS centers from both urban and rural area of Delhi. The information was obtained directly from TB patients and also cross checked in TB treatment card.

\section{Limitations}

MDR Tuberculosis patients were not included due to lack of resources. Only two DOTS centre from rural area come under the field practice area of community medicine department were included. The study area was selected according to convenience. We also not elicited any risk factor associated with HIV prevalence such as heterosexual relations with multiple partners, b) intravenous drug abuse and c) presence of concomitant STDs.

\section{CONCLUSIONS}

The prevalence of HIV infection among Tuberculosis patients in this study was $2.4 \%$ which is substantially lower than other states. Greater focus of health intervention should be required on reproductive age group and in area in which high immigration and overcrowding present. It is imperative that physician and DOTS provider taking care of TB patients should aggressively send category II patients for HIV testing.

\section{ACKNOWLEDGEMENTS}

The authors wish to thank all the subjects who participated in this study.

\section{REFERENCES}

1. Vijay $S$, Swaminathan $S$, Vaidyanathan $P$, Thomas $A$, Chauhan LS, Kumar P, et al. Feasibility of Provider-Initiated HIV Testing and Counselling of Tuberculosis Patients Under the TB Control Programme in Two Districts of South India. PLoS ONE 2009; 4(11): e7899.

2. Raizada N, Chauhan LS, Khera A, Sokhey J, Wares DF, Sahu S, et al. HIV Seroprevalence among Tuberculosis Patients in India, 2006-2007. PLoS ONE 2008 Aug 20;3(8): e2970.

3. National AIDS Control Organization. HIVIAIDS epidemiological surveillance and estimation report for the year 2005. http://www. nacoonline.org/fnlapil06rprt.pdf Retrieved 20/09/2011.

4. Agarwal SP and Chauhan LS. Tuberculosis control in India. New Delhi, India: Ministry of Health and Family Welfare, 2005. http://www.tbcindia.nic.in/pdfs/Tuberculosis $\% 20$ Control\%20 in\%20India-Final.pdf. Retrieved 20/06/2014.

5. Swaminathan S, Ramachandran R, Baskaran G, Paramasivan CN, Ramanathan U, Venkatesan P, et al. Risk of development of tuberculosis in HIV-infected patients. Int $\mathrm{J}$ Tuberc Lung Dis 2000; 4: 839-844.

6. TB India 2011. RNTCP Annual Status Report. Delhi: CTD DGHS and MOHFW publication; March 2010. 175p. http://www. tbcindia.org. Retrieved 21/06/2011.

7. World Health Organization. Guidelines for HIV Surveillance among Tuberculosis Patients. 2nd ed. Geneva, Switzerland: World Health Organization; 2004.

8. Sawant SS, Agrawal SR, Shastri JS, Pawaskar M and Kadam P. Human immunodeficiency virus infection among tuberculosis patients in Mumbai. J Lab Physicians 2011; 3:12-14.

9. Gupta AK, Singh GP, Goel S, Kaushik PB, Joshi BC and Chakraborty S. Efficacy of a new model for delivering integrated TB and HIV services for people living with HIVIAIDS in Delhi - case for a paradigm shift in national HIV/TB cross-referral strategy. AIDS Care 2014; 26(2):137-141.

10. TB India 2012. RNTCP Annual Status Report. CTD DGHS and MOHFW publication; March 2012. 185p. http://www.tbcindia. org. Retrieved 21/06/2014.

11. Uhler LM, Kumarasamy N, Mayer KH, Saxena A, Losina E, Malaisamy M, et al. Cost-Effectiveness of HIV Testing Referral Strategies among Tuberculosis Patients in India. PLoS ONE 2010; 5(9): e12747.

12. Shrivastava SR and Shrivastava PS. HIV-tuberculosis interface: A comparison of collateral prevalence of HIV and tuberculosis in an urban health centre. Ann Trop Med Public Health 2013; 6:290-296.

13. Sharma SK, Saha PK, Dixit $Y$, Siddaramaiah $N H$, Seth $P$ and Pande JN. HIV seropositivity among adult tuberculosis patients in Delhi. Indian J Chest Dis Allied Sci 2000; 42:157-160.

14. Jain SK, Aggarwal JK, Rajpal S, and Baveja U. Prevalence of HIV infection among tuberculosis patients in Delhi - A sentinel surveillance study. Ind J Tub 2000; 47:21.

15. Sharma SK, Aggarwal G, Seth P and Saha PK. Increasing HIV seropositivity among adult tuberculosis patients in Delhi. Indian J Med Res 2003; 117:239-242.

16. Piramanayagam $P$, Tahir $M$, Sharma SK, Smith-Rohrberg $D$, Biswas A and Vajpayee M. Persistently high HIV seroprevalence among adult tuberculosis patients at a tertiary care centre in Delhi. Indian J Med Res 2007; 125(2):163-167.

17. Bahl R, Singh B and Singh R. Prevalence of HIV infection among patients of pulmonary tuberculosis attending chest diseases hospital, Jammu (Jammu and Kashmir). Indian J Community Med 2007; 32(4):288-289.

18. Pennap GR, Makut MD, Gyar SD and Owuna G. Seroprevalence of HIVIAIDS in Keffi and Environs. Nig J Microb 2006; 20:1141-1146.

19. Deswal BS, Bhatnagar D, Kumar D and Deshpande VR. A Study of Prevalence of HIV in Tuburculosis Cases. Indian J Community Med 2002; 27 (2):4-6.

20. Jaiswal RK, Srivastav S and Mahajan H. Socio demographic profile of TB-HIV coinfected patients in Bundelkhand region, Uttar-Pradesh. Nat Jn Med Research 2012; 2(2):149-151. 
21. Kataria VK, Rosha D and Maudar KK. HIV and tuberculosis coinfection in referral chest hospital. Med J Armed Forces India 2000; 56: 298-300.
22. Wang L, Liu W, Wang L, Wang $Y$ and Wu Z. HIV Prevalence Among Pulmonary Tuberculosis Patients in Guangxi, China. J Acquir Immune Defic Syndr 2010; 53:61-65.

\section{Authors Contribution:}

VCS - Concept, design, definition of intellectual content, data collection and analysis, literature search, manuscript preparation; JD - Design and statistical

analysis and manuscript editing; RTC - manuscript edition preparation and review; PB - data collection, manuscript editing; CK - statistical analysis, Manuscript

preparation, reviewed the manuscript.

Source of Support: None declared, Conflict of Interest: None declared. 